\title{
Resenha
}

\section{0 pensamento de Donald Schön: reflexões a partir da obra de Tardif, Borges e Malo}

\author{
Denise Gisele de Britto Damasco \\ Universidade de Brasília
}

TARDIF, Maurice; BORGES, Cecilia; MALO, Annie. Le virage réflexif en éducation: Où en sommes-nous 30 ans après Schön ? Bruxelas: Editora De Boeck Supérieur [Pédagogie en développement], 2012.

Tive contato com a obra Le virage réflexif en Education: où en sommes-nous 30 ans après Schön? originalmente escrita em francês, no primeiro dia de meu estágio de doutorado sanduíche na Universidade de Montréal - UdeM, no Québec, Canadá, em fevereiro de 2013. Em minha primeira conversa com o professor Maurice Tardif, ao apresentar meu tema de doutorado, ele me entregou seu livro, recém-lançado. Considero Donald Schön um dos autores mais influentes no campo da reflexão e já havia tido contato com sua obra, tendo em vista meu interesse pela formação docente, profissionalização docente, ensino e aprendizagem de línguas.

Três professores da Faculdade de Educação da UdeM são os organizadores desta obra. Introduzem-na afirmando que esta coletânea de artigos nasceu do desejo de compreender a virada reflexiva iniciada por Schön há trinta anos na área da pesquisa sobre o ensino e mais amplamente na educação. As seguintes questões foram colocadas para seleção dos artigos para essa coletânea: Qual sentido é preciso dar à virada reflexiva? Qual a consequência disto para a profissão docente e para a formação docente? Tal orientação ainda é pertinente atualmente para se pensar a atividade e a formação profissional dos professores?

0 que significa a virada reflexiva? Conscientes de que em educação não há um paradigma, os organizadores dessa obra destacam que o termo 'virada' aponta para um momento cujas características são paradigmáticas, devido à velocidade de expansão temporal e espacial de tais ideias. Assim, "há um momento antes de Schön e um depois de Schön" (p.08), que tem em seu livro The Reflective Practitioner: How professionals think in action, publicado em 1983, um marco desta virada. Tardif, Borges e Malo (2012, p. 08) explicitam que os elementos que surgiram depois de Schön expressam "a importância do pensamento do professor, seus saberes, seu julgamento e suas decisões na ação". Antes de Schön, tais elementos eram ignorados, por exemplo, nos Estados Unidos. Na Europa, o docente não era considerado "como um profissional dotado de um pensamento complexo e de uma 
atividade autônoma". (Tardif; Borges; Malo, 2012, p. 09)

De fato, no campo educacional, o pensamento de Schön sobre reflexão se difundiu por diversos continentes, de maneira acelerada no início dos anos 1990, seja no debate referente às políticas educacionais, seja na formação docente, na prática avaliativa, inclusive em cursos de licenciatura em pedagogia a distância. Sua obra promoveu rupturas em relação ao que existia até então, sobretudo ao ressaltar que a reflexão, como uma competência desenvolvida, facilita uma constante melhora na atuação do docente em sala de aula. Scaramucci (2006) salienta o que o paradigma da racionalidade prática traz à luz: a sala de aula como um contexto complexo e imprevisível, cujas soluções advêm da problematização e da reflexão em substituição do paradigma da racionalidade técnica e instrumental que concebe "a sala de aula como um ambiente previsível e estático", levando o docente a buscar receitas de resolução de problemas sem reflexão. (Scaramucci, 2006, p. 50)

Os organizadores desta obra chamam a atenção para três avanços intelectuais na obra de Schön (1983): o primeiro avanço crítico refere-se aos modelos de formação da época, em que há uma visão instrumental e aplicacionista da formação dos profissionais. Contra essa lógica de formação, Schön (1983) sustenta que “a ação constitui o lócus privilegiado para toda profissão; ela deveria se constituir, assim, no elemento central das formações universitárias" (Tardif; Borges; Malo, 2012, p. 09). Consequentemente, vê-se, duas décadas posteriormente, segundo os organizadores dessa obra, o surgimento de relações mais estreitas entre as universidades e as escolas, sobretudo, na acolhida de estagiários. Veem-se, ainda, pesquisas colaborativas sobre as práticas docentes em sala de aula e na escola.

0 segundo avanço intelectual presente em Schön (1983) é um avanço heurístico e metodológico, no qual, por meio de diversos estudos, conclui-se que para compreender a atividade profissional é necessário estudar a prática profissional. Os profissionais não são apenas pessoas consideradas como "idiotas cognitivos ou técnicos que seguem regras definidas, mas eles pensam sua ação ao realizá-la, eles a constroem, improvisam a partir dela mesma, inovam, (relenquadram seus problemas, dando sentido aos mesmos e agem de maneira sempre criativa para resolvê-los". (Tardif; Borges; Malo, 2012, p. 09)

0 terceiro avanço intelectual apresentado por Tardif, Borges e Malo (2012) é um avanço científico, que realça as dimensões cognitivas da atividade profissional: "Schön mostra que essa atividade necessita de uma inteligência profissional em ação durante a ação" (Tardif; Borges; Malo, 2012, p. 09). Schön (1983) traz assim categorias presentes no discurso científico e político internacional sobre ensino, formação de professores e profissão docente, tais como: prático reflexivo, prática reflexiva, reflexão, reflexão-na-ação e reflexão-sobre-a-ação, construção de problema (Problem setting), aprendizagem pela ação, entre outras categorias.

0 avanço crítico nos modelos de formação e na pesquisa, a partir do pensamento de Schön, faz com que o docente seja compreendido como um profissional que 
produz saberes e, por meio deles, oriente sua prática profissional. Por meio da reflexão, instaura-se uma certa lógica da racionalidade prática, contrária à racionalidade técnica e instrumental presente em pesquisas e programas educacionais vigentes. Tardif, Borges e Malo (2012, p. 10) afirmam que "a visão schöniana permite assim atualizar a tradição educativa oriunda de Dewey sobre aprendizagem pela experiência e o papel da reflexão no conhecimento". Desta forma, o impacto internacional da obra de Schön (1983), nas duas décadas seguintes, se faz sentir no plano da pesquisa, das reformas da formação de professores e da identidade profissional dos professores.

Aderindo a Schön ou contestando-o (1983), de acordo com os organizadores dessa coletânea, diversos pesquisadores e formadores universitários comparam seus trabalhos e programas de formação ao modelo do prático reflexivo, quer se aproximando, quer se diferenciando dele. A reflexão torna-se, assim, uma competência primordial para o docente. Tardif, Borges e Malo (2012, p. 11) destacam ainda que "o prático reflexivo deixa de ser um conceito, torna-se então uma categoria política e institucional que reestrutura as instituições, os programas, as práticas e os dispositivos de formação até o ensino". Tais organizadores dessa obra retomam o fato de o profissional docente parar de se enxergar como um artesão, um mero técnico ou funcionário. Este professor é profissional, porque é reflexivo e capaz de refletir. Essa virada reflexiva "enobrece a profissão docente". (Tardif; Borges; Malo, 2012, p. 11)

Apesar de reconhecer que essa virada profissional é valorizada por pesquisadores, justamente por testemunhar a inteligência de profissionais, constatou-se que ela se propagou de maneira diluída e fragmentada ao longo desses últimos 30 anos. Assim, essa coletânea se organiza em duas partes, contando com dez capítulos. A primeira parte apresenta o debate propriamente dito sobre a virada reflexiva, tendo em seu primeiro capítulo ${ }^{1}$ uma síntese inédita em língua francesa dos trabalhos dos 20 últimos anos no mundo anglosaxão sobre as abordagens teóricas e as definições de reflexão. Maurice Tardif apresenta no segundo capítulo da primeira parte ${ }^{2}$ dessa obra a acolhida e a interpretação da virada reflexiva na área educacional. Retoma o contexto científico e intelectual de cujo seio emergiu a ideia do prático reflexivo ao longo dos anos 1980. Para esse autor, o impacto da virada reflexiva na educação é acompanhado de um empobrecimento de diversas tradições do pensamento reflexivo que outrora uniam a educação às ciências sociais e humanas. Colocase a favor de uma aproximação intelectual capaz de reintegrar tais tradições com uma visão renovada e rica de reflexão em proveito do estudo sobre o trabalho docente.

1. Capítulo intitulado Un cadre conceptuel pour mieux comprendre la littérature sur la réflexion en enseignement, par Catherine Beauchamp, de l'Université Bishop's. (traduzido para o inglês por Charly Bouchara).

2. Capítulo intitulado Repenser le "praticien réflexif à la lumière des traditions de la pensée réflexive. Maurice Tardif é professor da Universidade de Montréal no Canadá. 
No capítulo 03 da primeira parte dessa obra, Bernard Schneuwly ${ }^{3}$ propõe "um estudo crítico da penetração acelerada, desde o início dos anos 1990, do pensamento de Schön na Europa e, particularmente, nos países francófonos" (Tardif; Borges; Malo, 2012, p. 14). Lança-se nas deformações conceituais e nas mudanças metafóricas ao longo do uso das noções de reflexão, prático reflexivo e de reflexão-na-ação. Este autor evidencia os mecanismos discursivos e ideológicos que propiciam uma generalização abusiva de tais conceitos.

No quarto capítulo ${ }^{4}$. Thierry Piot ${ }^{5}$ discute como "a linguagem é um instrumento dinâmico que permite a aproximação reflexiva na atividade docente dos professores" (Tardif; Borges; Malo, 2012, p. 14). No quinto capítulo6, seu autor, Guy Bourgeault, "ao se inspirar livremente na obra de Paul Ricoeur, analisa as tensões que caracterizam a reflexividade ética". (Tardif; Borges; Malo, 2012, p. 14)

Na segunda parte dessa obra, seus organizadores apresentam a reflexão entre o trabalho e a formação. No sexto capítulo7 , o Professor Claude Lessard" "aborda a reflexão a partir das controvérsias profissionais" (Tardif; Borges; Malo, 2012, p. 15). Para este autor, tais controvérsias "são susceptíveis de contribuir para elaboração e difusão de regras práticas profissionais racionais e razoáveis dentro da profissão docente [...] constituindo uma aproximação coletiva de aprendizagem da reflexão profissional". (Tardif; Borges; Malo, 2012, p. 15)

No sétimo capítulo9, tem-se uma discussão sobre o papel e o lugar da pesquisa na formação para a reflexão. Seu autor, Bernard Wetzel ${ }^{10}$, “situa o desenvolvimento dessa virada reflexiva iniciada por Schön dentro do movimento de profissionalização do ensino [...] Em seguida, interessa-se pelo desafio que representa a integração da pesquisa em formação profissional de nível tecnológico e universitário" (Tardif; Borges; Malo, 2012, p. 15). No oitavo capítulo"11, dois autores, Desjardins ${ }^{12}$ e Boudreau ${ }^{13}$, discutem a formação reflexiva dos estudantes dos programas de formação de professores. Tais autores se voltam para a escrita dos estudantes, lembrando "a responsabilidade das equipes de formadores na definição das exigências esperadas em matéria de escritura reflexiva por parte dos estudantes" (Tardif; Borges; Malo, 2012, p. 16). Outro professor da Universidade

3. Capítulo intitulado Praticien réflexif, réflexion et travail enseignant: l'oubli de l'objet et des outils d'enseignement. 0 professor Schneuwly é também presidente da seção de educação da Universidade de Genebra, na Suíça.

4. Capítulo intitulado Le langage, organisateur et instrument de la réflexivité professionnelle des enseignants.

5. Professor em educação e diretor do Centro de estudos e de pesquisa em educação da Universidade de Caen, na França.

6. Capítulo intitulado Éthique professionnelle et réflexivité : quelle connivence?

7. Capítulo intitulado Controverses éducatives et réflexivité: quant-à-soi personnel ou professionnalisation?

8. Professor na Universidade de Montréal e Presidente do Conselho Superior de Educação do Québec.

9. Capítulo intitulado Réflexivité et formation professionnelle des enseignants: actualités d'un paradigme en construction.

10. Decano de pesquisa na Haute École Pédagogique BEJUNE.

11. Capítulo intitulado Les écrits réflexis en formation: de la pratique des étudiants à la nécessité d'une cohérence programmée.

12. Vice-decana de formação da Universidade de Sherbrooke (Québec, Canadá).

13. Pesquisador da Universidade de Sherbrooke. 
de Sherbrooke se responsabiliza pelo nono capítulo ${ }^{14}$ dessa obra, Enrique Correa Molina, juntamente com a professora da Universidade de Montréal, Colette Gervais. Ambos abordam neste capítulo as reflexões de estagiários sobre suas práticas.

0 último capítulo ${ }^{15}$ dessa obra relaciona as novas tecnologias de comunicação (TICs) a Schön, tendo em vista que o início da utilização dessas tecnologias também foi nos anos 1980, segundo Tardif, Borges e Malo (2012). Os autores desse capítulo, Thierry Karsenti, Michel Lepage ${ }^{16}$ e Simon Collin ${ }^{17}$ se basearam em uma síntese de resultados de quatro estudos realizados entre 2001 e 2009. Tais autores mostram que, "se a utilização das TICs se mostra frutífera para o pensamento reflexivo dos estudantes, há muitos desafios para se enfrentar quanto à implantação, coerente e compartilhada pelo conjunto de formadores de um mesmo programa, de dispositivos tecnológicos de prática reflexiva". (Tardif; Borges; Malo, 2012, p. 16)

A leitura deste capítulo 10 foi particularmente relevante para minha pesquisa doutoral na medida em que pude me aproximar de uma crítica aos fóruns eletrônicos de discussão em relação aos grupos eletrônicos de discussão. Karsenti, Lepage e Collin listam algumas vantagens dos grupos eletrônicos de discussão, como "seu efeito multiplicador sobre o número de mensagens recebidas" (Tardif; Borges; Malo, 2012, p. 205) pelos participantes de um debate sobre um tema, em contraposição ao fórum de discussão, "já que o estudante deve se conectar sobre o fórum e clicar sobre uma mensagem para consultá-la" (Tardif; Borges; Malo, 2012, p. 205). Ao olhar para o início da internet, e a partir da experiência-piloto realizada na Universidade de Montréal com o grupo eletrônico de discussão e o fórum eletrônico de discussão, tais autores concluem que o grupo de discussão tem "a vantagem de poder reunir todos os estagiários a partir de um só clique, em sua caixa postal. Este modo de comunicação oferece igualmente uma comunicação crescente, favorecida pela ausência de restrições espaciais ou temporais" (Tardif; Borges; Malo, 2012, p. 208). 0 grupo eletrônico de discussão é a forma privilegiada de comunicação para a formação prática dos estagiários na Universidade de Montréal, segundo os autores, tendo em vista "que permite guardar traços escritos de uma mensagem que pode, antes de tudo, ter sido escrita e editada em modo de tratamento de texto". (Tardif; Borges; Malo, 2012, p. 208)

Tardif, Borges e Malo pretendem mostrar com essa coletânea de artigos que "a ideia de 'prático reflexivo' parece estar prestes a se tornar um simples slogan político" (Tardif; Borges; Malo, 2012, p.17). Entendo que a expressão "slogan político" engloba também um slogan pedagógico na medida em que o reducionismo do pensamento de Schön al levou a uma valorização da prática em

14. Capítulo intitulado Contenus alimentant la réflexion de stagiaires en début de formation.

15. Capítulo intitulado Potentiel des TIC pour la pratique réflexive en stage: bilan de quatre expériences pilotes réalisés au cours des 10 dernières années.

16. Ambos os professores são da Universidade de Montréal.

17. Professor na Universidade de Québec em Montréal. 
detrimento do adensamento teórico, b) legitimou a formação contínua do docente como treinamento cl e, finalmente, camuflou a precarização do trabalho docente ao aceitar a substituição do docente pelo monitor e/ou instrutor, sobretudo em contexto de escolas livres de idiomas no Brasil a partir do final dos anos 1990, período em que o mercado de trabalho foi caracterizado por novas opções de modalidades flexíveis de contratação laboral por escolas e empresas. Linguistas aplicados ao ensino de línguas discutem também sobre o possível excesso de "encorajamento do individualismo", reforçado por Schön com a metáfora da reflexão como espelho e da hipervalorização da prática em detrimento de uma discussão coletiva em contextos educacionais. (Gimenez, 2004, p.180)

Este balanço realizado por Tardif, Borges e Malo, 30 anos após a obra de Schön, suscita assim a necessidade de se confrontarem os limites científicos, profissionais e educativos oriundos das diversas potencialidades intelectuais e práticas que decorrerem dessa virada reflexiva.

\section{REFERÊNCIAS}

SCHÖN, Donald. The reflective practitioner. New York : Basic Books, 1983.

TARDIF, Maurice; BORGES, Cecilia; MALO, Annie. Le virage réflexif en éducation : Où en sommes-nous 30 ans après Schön ? Bruxelas : Editora De Boeck Supérieur [Pédagogie en développement], 2012.

GIMENEZ, Telma. Tornando-se professores de inglês: experiências de formação inicial em um curso de Letras. In: ABRAHÃO, Maria Helena Vieira (org.). Prática de Ensino de Língua Estrangeira: experiências e reflexões. Campinas, SP: Pontes Editores, ArteLíngua, 2004.

SCARAMUCCI, Matilde V. Ricardi. 0 professor avaliador: sobre a importância da avaliação na formação do professor de língua estrangeira. In: ROTRAVA, Lúcia; SANTOS, Sulany Silveira (orgs.). Ensino e Aprendizagem de Línguas: Língua Estrangeira. ljuí: Ed. Unijuí, 2006, [Coleção linguagens].

Recebido em junho de 2013

Aprovado em julho de 2013

Denise Gisele de Britto Damasco é graduada em Letras, mestre e doutoranda em Educação pela UnB e professora da Secretaria de Educação do Distrito Federal, com experiência em gestão escolar de Centro Interescolar de Línguas. E-mail: denise.damasco@ggmail.com 